\title{
An Empirical Study of Service Delivery within the Provincial Hospital of Kwa-Zulu Natal South Africa-A case Study
}

\author{
A. Deen, R. Balkaran* \\ Durban University of Technology, South Africa \\ *rishi@dut.ac.za
}

\begin{abstract}
Health care services are an essential component of South African government policy and this is regulated by the Health Act, Act 61 of 2003. The study explores the services offered by the Provincial Hospital KwaZulu Natal, South Africa in relation to service delivery and management practices. The key participants to the study are the patients and staff of the hospital. A structured questionnaire to the patients and departmental heads of the hospital was applied. A structured interview was conducted with strategic level management of the hospital. The results of the study were organized thematically and were triangulated between the results of the various data collecting instruments. A presentation of graphs and tables would be used to facilitate the results of the data. The paper provides sound conclusions and recommendations for efficient and effective management and service delivery within the provincial hospital and which are applicable to many of the provincial hospitals in the country.
\end{abstract}

Keywords: Service delivery, hospital, South Africa

\section{Introduction}

Batho Pele principles, which means "people first "are a set of principles that enshrines amongst others the need to deliver efficient and effective services to its people. The South African government places this at the forefront of its policy within the public sector. Health care services are an essential component of government policy and the Health Act, Act 61 of 2003, regulates this. The study explores the services offered by the Provincial Hospital Kwa-Zulu Natal, South Africa in relation to service delivery and management practices. The National Health Act, 2003 provides a framework for a single health system for South Africa. It highlights the rights and responsibilities of health providers and healthcare users, and ensures broader community participation in healthcare delivery from a health facility level up to national level. It establishes provincial health services and outlines the general functions of provincial health departments (South African Government Information, 2008). The provincial hospital in KwaZulu Natal will be evaluated in respect of its management practices and service delivery. Chatsworth is a large township in Durban, South Africa. This area was created because of the Apartheid Government and the Group Areas Act in the late 1960's. It was designated for use by the Indian population only, and by those who were removed from their initial areas of occupation due to racial segregation and the implications of the Group Areas Act. Because of this, parts of Chatsworth are still an area of extreme poverty separated from the developed resort areas of Durban. However, there are also large middle class and wealthy areas. The role of provincial hospitals therefore become more crucial and challenging in respect of service delivery. The Batho Pele principles drive an approach, which are typical to the concept of hospitality. Du Toit, Knipe, Van Niekerk, Van der Walt. In addition, Doyle (2002: 109) emphasizes the similarities with hospitality in the following headings:

Service standards: citizens must be informed about the level and quality of the services they will receive in order for them to know what to expect. This implies that public servants must deliver the level and quality of services they have undertaken to provide. Failing to do so means that citizens have a right to complain and demand quality services. In the hospitality industry, Kotas, Teare, Logie, Jayawardena and Bowen (1996) emphasize the importance of meeting customer needs, and when there are no gaps between what the customer expects and what the customer gets, quality is present.

Access: citizens have a legitimate right to equal access to services, and public servants must not withhold that right from them. This asserts that all citizens should have equal access to the services to which they are entitled. Whitney (1990) suggests in the principle of rights, that right is not based so much on the individual's guest's status as it is upon the fact that the guest is a human being, and life itself is a moral entitlement. 
Courtesy: citizens should be treated with courtesy and consideration. According to this principle, public servants must treat every citizen with courtesy and consideration, irrespective of the social status of the person. Everyone must be treated with courtesy. Berger \& Brownwell (2009) believes every employee's activities, no matter what position they hold, affect the customer.

Value for money: citizens have the right to demand that the services they receive are real value for money paid for them. This makes public servants responsible for providing efficient, effective and economic services - value for money. Ford \& Heaton (2000) highlights the most important component of service delivery in the hospitality industry, are the people in the organization that interact with customers or guests, and it is attitude, friendliness and genuine concern of the organization staff that determine both the value and the quality of the experience of the guest. The Batho Pele principles represent the people, and it emphasizes their right to how they should be treated when receiving health care and these fundamental principles are in conjunction with the bill of rights within the constitution.

The Batho Pele is not an "add-on" activity. It is a way of delivering services by putting citizens at the centre of public service planning and operations. It is a major departure from a dispensation, which excluded the majority of South Africans from government machinery to the one that seeks to include all citizens for the achievement of a better-life-for-all through services, products, and programs of a democratic dispensation Fraser-Moleketi (2007). According to Nzimakwe \& Mpehle (2012) the aim introducing these principles was not only to transform the culture of public service delivery, but also to prescribe citizens' service packages, set service standards that can be benchmarked against international standards, and to ensure that citizens are the central focus in service delivery, and therefore are put first.

\section{Provincial Hospital in KwaZulu Natal}

The mission of the Provincial Hospital is to deliver a comprehensive mainly curative health service of a high standard to all people in their region, with compassion and empathy, in a cost effective manner (Patient Information Booklet). This mission is in endorsed by the KwaZulu-Natal Department of Health (2001) as their mission is to develop a sustainable, co-ordinated, integrated and comprehensive health system at all levels, based on the primary health care approach through the district health system. According to KwaZulu-Natal Department of Health (2001), the core values of the provincial hospital are -

- Trust built on truth, integrity and reconciliation;

- Open communication, transparency and consultation;

- Commitment to performance; and

- Courage to learn, change and innovate.

These core values in conjunction with the Batho Pele Principles indicate that citizens are entitled to courtesy, consideration, transparency and value for money when they are provided with health care. Fraser-Moleketi (2007) further emphasizes that it is a simple and transparent mechanism, which allows citizens to hold public servants accountable for the level of services they deliver. The Provincial Hospital is designated a District and Regional hospital. Therefore, the Provincial Hospital has to provide support to health workers in clinics the surrounding area of Chatsworth, provide community services, both in terms of clinical care and public health expertise. the Provincial Hospital has to also provide first level hospital care for the district and be the place of referral from clinics, community health centres in the southern region and be responsible for referring patients to higher levels of care when necessary (Chetty, 2009).

\section{Methodology}

Research methods are no more than tools to the trade. There are various types of data collecting techniques and acquiring knowledge, such as telephonic interviews, personal interviews, participant collecting, and the use of field workers who are trained to go out and collect the required information Moore (1983). This research focuses on a provincial hospital in the southern area of Durban, KZN, and data was collected through a survey-using questionnaire and structured interviews. Johns \& Lee-Ross (1998) believe that research projects within service organizations need to be dynamic enough to cope with the changing environmental conditions. Service organizations like hotels are not scientific laboratories with controlled conditions. Hospitals have a similar environment lacking in controlled conditions with specific reference to patients in need of care and both staff and patient are not always willing to participate in research projects. Therefore, research projects must have contingency plans and 
especially within the hospital service organization, which is labor intensive, employees, are constantly engaged in delivering services and treatment to patients directly. The availability of employees and hospital staff are usually very scarce therefore, the need to be flexible becomes critical. Questionnaires are one of the most widely used social research techniques. Blaxter, Hughes \& Tight (2006) explain that the idea of formulating precise questions, for those whose opinions or experience interested in, is an obvious strategy for finding answers to the questions related to the research. Bless et al (2006) contend that questionnaires are easily standardized and are a low drain on time and finances. Moore (1982) states that the primary function of surveys is to collect information, which then can be analyzed to produce conclusions. A structured questionnaire to the patients and department heads of the provincial hospital was applied. Bless et al (2006) cite the advantages of questionnaires as easy standardization; quick turnaround time; cost effective and requiring very little training for field workers. A structured interview was conducted with strategic level management of the provincial hospital.

According to Neuman (2006), interviews to gather information occur in many settings. Neuman continues that employers interview prospective employees, medical personnel interview patients, mental health professionals interview clients, social service workers interview the needy, reporters interview politicians and others, police officers interview witnesses and crime victims, hence a survey research interviewing is a specialized kind of interviewing. Neuman (2006) further states that as with most interviewing, its goal is to obtain accurate information from another person. According to Chetty (2010) there are approximately 500 patients that are cared for daily within the outpatients department of the provincial hospital. A structured questionnaire was targeted to the patients within the outpatients department of the provincial hospital. A sample size of $65 \%$ (325 patients) was sought. A $61 \%$ (306 patients) return rate was achieved. A population is a group of cases such as people, managers and organizations. A target population can become extremely costly and time consuming if one has intentions to cover the entire population. Hence, a sample would be the next option. Hansen, Hurwitz \& Madow (1993) define a sample as a subset of a population selected to obtain information concerning characteristics of the population. Goldenberg (1992) suggests that specification of the sampling frame translates a rather abstract idea of the purpose and orientation of the research into a far more grounded or concretely spelled out set of rules concerning how data will be gathered and what basis there would be for generalization from them to the relevant population. Hence, Johns \& Lee-Ross (1998) outlines that sample are a smaller group that represents the whole population.

\section{Analysis and Results}

The information obtained from the survey questionnaires and structured interviews, responded to the critical areas of the study, which were grouped into two fundamental themes: service delivery, management processes and practices. The survey questionnaires to the patients, Heads of Department and the structured interview conducted with the senior managers of the hospital were originally intended to be compartmentalised and organised into convenient sets of information to the relevant themes of the study respectively. The data yielded through these mechanisms however, materialized in a very integrated and comprehensive way, which became relevant to all three themes of the study at varied levels. In order to enhance the coherence of the presentation of results, data were triangulated and viewed as a whole.

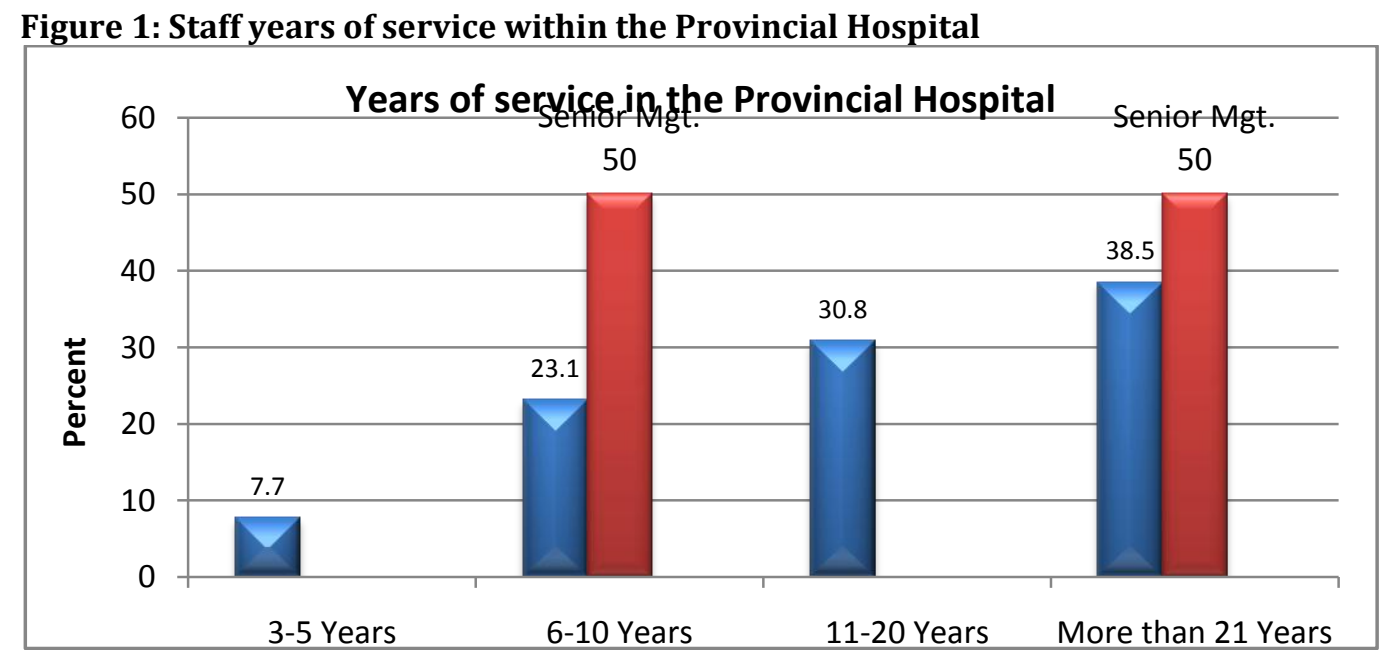


Figure 1 indicates that more than two-thirds of the respondents (69.3\%) had more than 10 years of experience at the hospital. This is useful as it indicates that the sample has many years of experience and that the responses should be an accurate source of information. Senior Management identified in Figure 1 reveals that $50 \%(\mathrm{n} 1)$ have between 6-10 years of experience and the other $50 \%(\mathrm{n} 1)$ have experience in excess.

Figure 2 indicates the most common areas that were visited by the respondents of the Provincial Hospital. Nearly two-thirds of the respondents (63.4\%) indicated that their primary location (of visit) was Outpatients. A quarter of the respondents visited the Pharmacy (16.7\%). 8.5\% of the respondents were from the Wards. $5.6 \%$ of the respondents visited the clinic, $4.6 \%$ of the respondents visited the medical outpatients department and only $0.7 \%$ of the respondents visited the provincial hospital for a general query.

\section{Figure 2: Areas visited most by Patients}

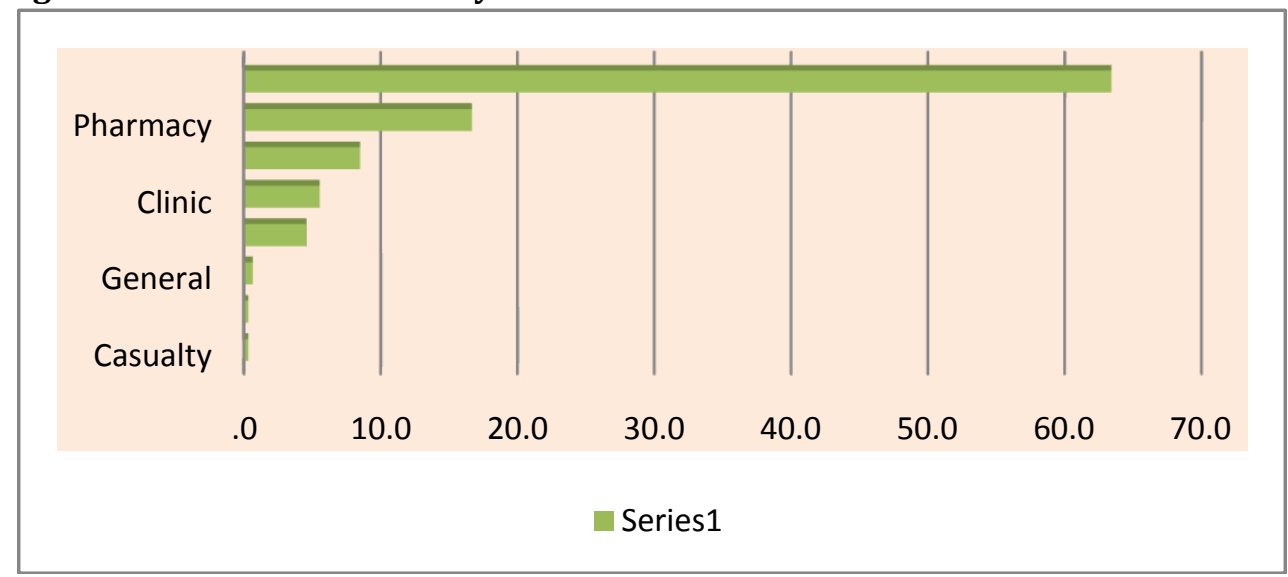

\section{Theme: 1Service Delivery}

Figure 3: Specified departments that patients indicated that they were unhappy with

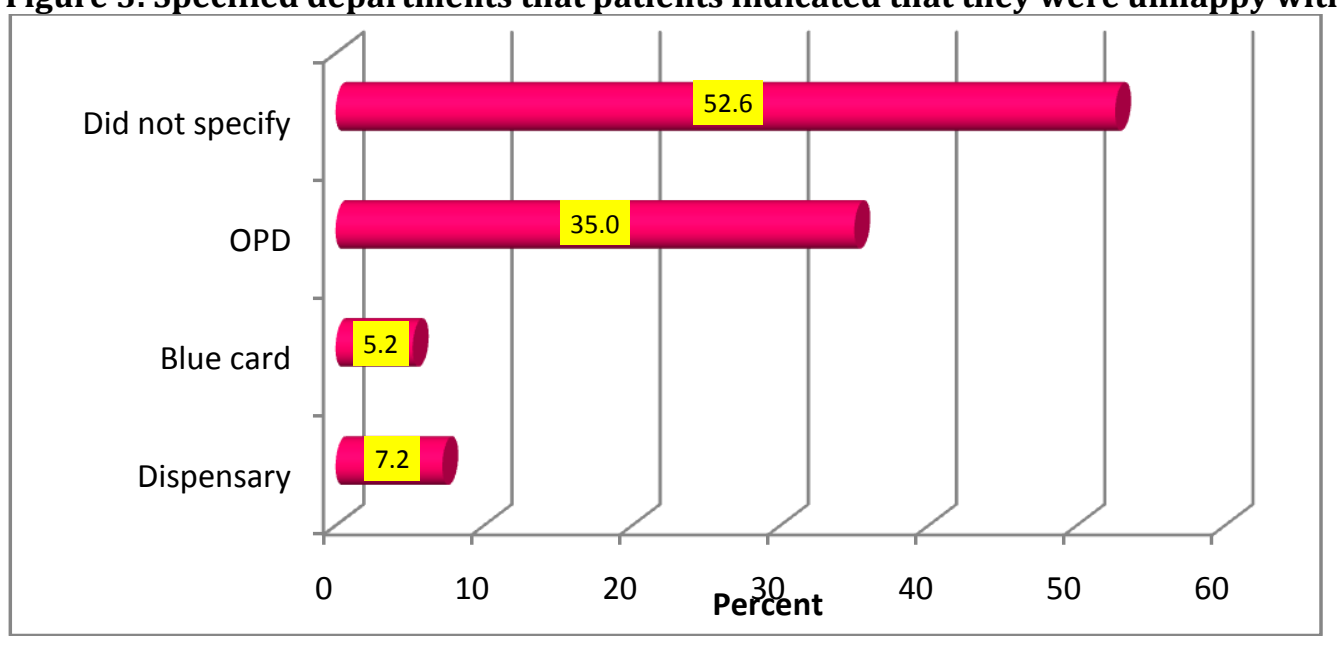

Departments That Patients Indicated They Were Unhappy With: More than half of the respondents $(52.6 \%)$ did not specify the area that caused the longest delays in Figure 3. However, others (35.0\%) indicated that the OPD was the leading department of dissatisfaction followed by the dispensary (7.2\%) and the blue card area (5.2\%).The purpose of this analysis was to display a consistency with the management survey and patient survey. The findings reveal that OPD was the leading department of dissatisfaction. Figure 3 indicates that this department is also the most frequented department by the patient. 
Figure 4: Management view on challenges faced with patient visitors

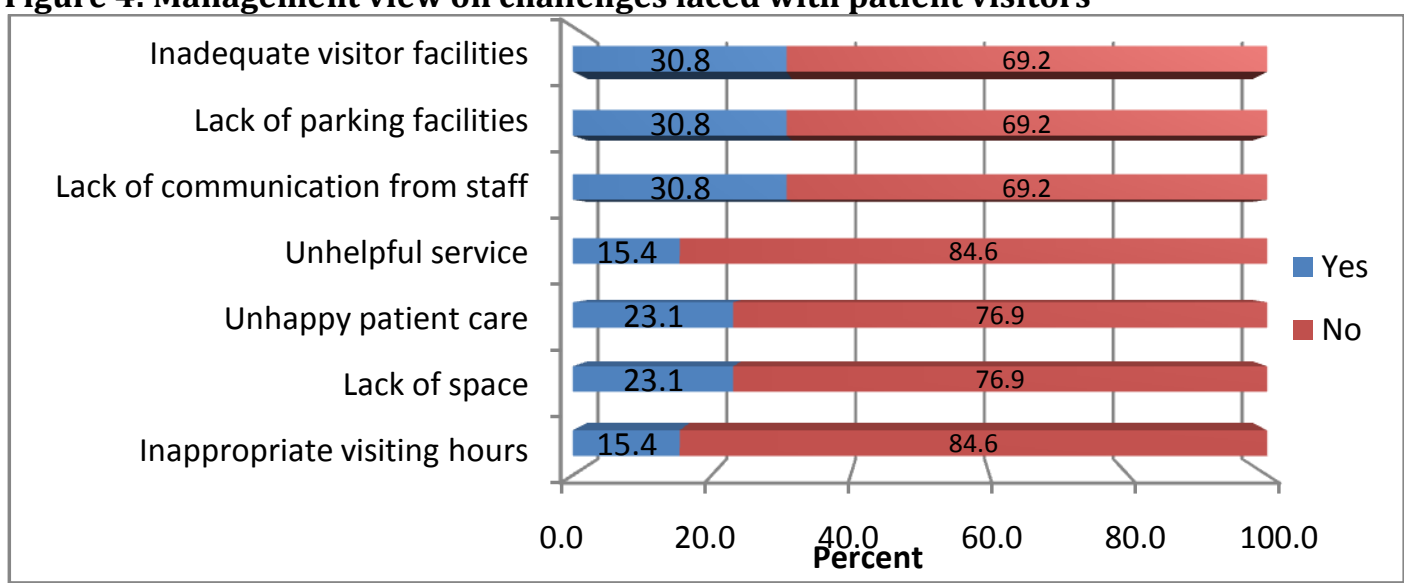

The key challenges that emanate from Figure 4 are inadequate visitor facilities, lack of parking facilities, and lack of communication from staff. These difficulties places untold pressure on visitor and ultimately the patient.

Figure 5: The service experienced by the patients

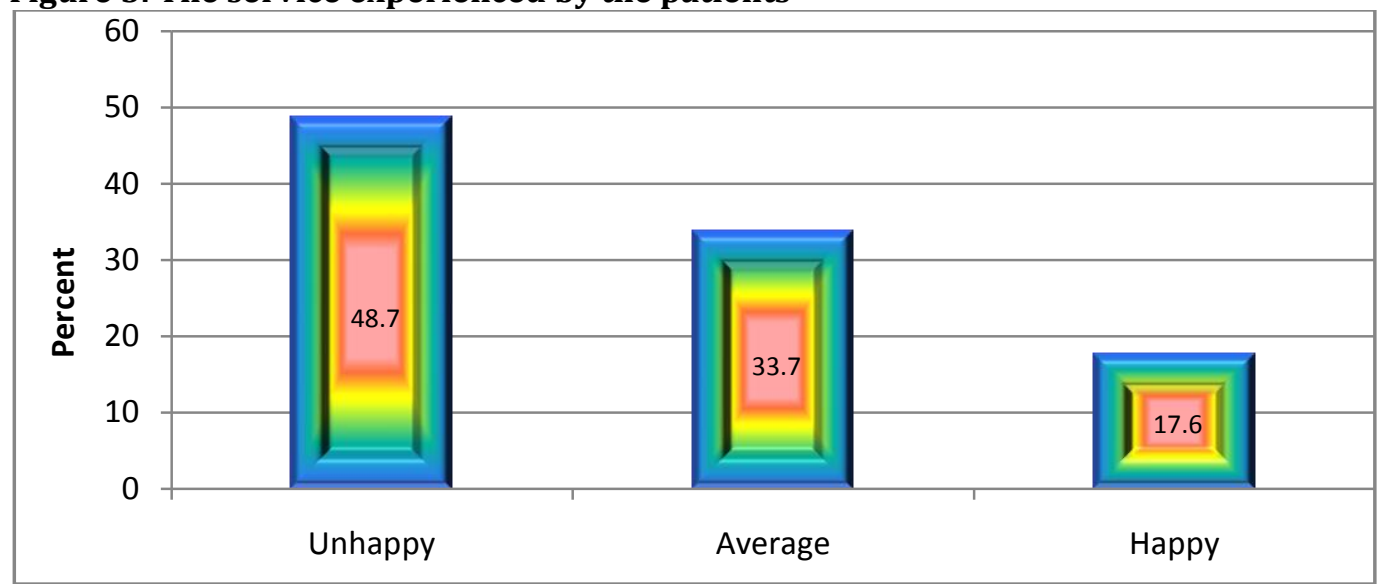

Figure 5 indicates perceptions of patients who visited the provincial hospital regarding the service experience. Nearly 3 times as many respondents were unhappy (48.7\%) with their hospital experience than there were those who were happy (17.6\%). These findings are consistent with the findings from the management survey and patient survey. Kotas et al (1996) confirms that service industries essentially offer a psychological experience that is ultimately enjoyed or endured by the guest or visitor.

\section{Figure 6: Time Lapse for treatment after Patient Arrival}

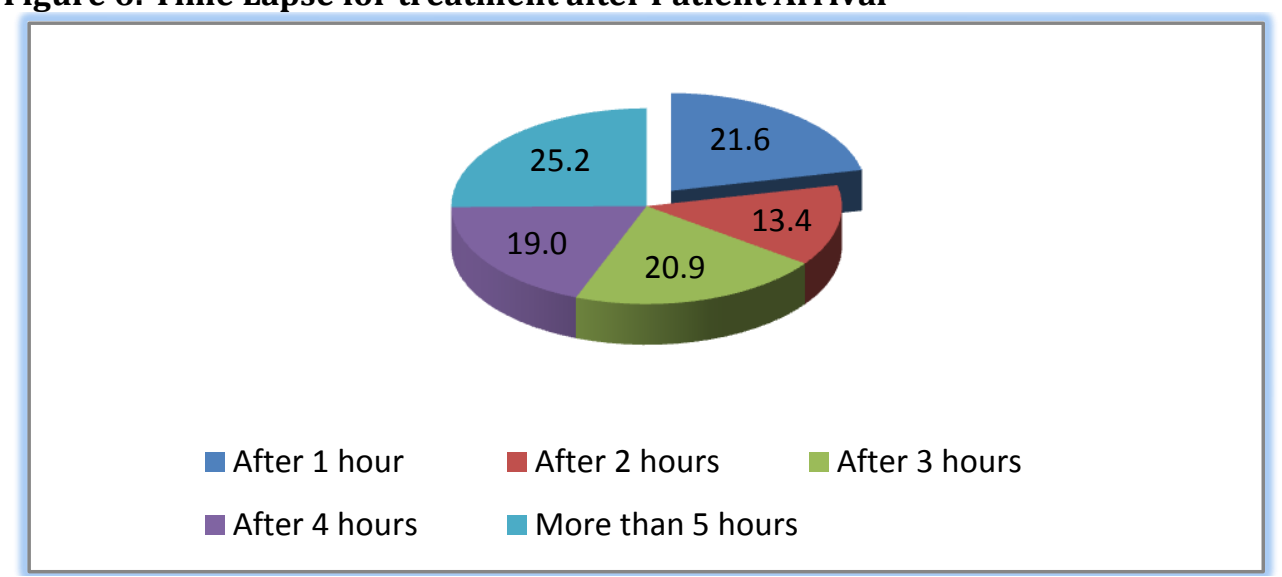


Waiting for treatment is an extremely stressful experience and Figure 6 reveals the waiting times and $25 \%$ of the patients wait for more than 5 hours to be treated. Another $19 \%$ receives treatment after 4 hours of waiting, $20.9 \%$ after 3 hours of waiting and $21.6 \%$ after 1 hour of waiting.

Figure 7 describes the attitude of staff experienced by the patient when they visit the hospital. Multiple responses were possible for the options in the figure above. $84.6 \%$ of respondents indicated that the hospital staff was kind and gentle and $88.6 \%$ of the respondents supported that staff were patient and concerned. Findings also reveal that $90.5 \%$ of the respondents indicate the staff was not aggressive and unconcerned and $75.5 \%$ of the respondents point out that staff was willing to help. Almost $10 \%$, of the respondents indicated that staff was aggressive and unconcerned; with $12.4 \%$ of the respondents revealing that, staff was unkind and rude.

Figure 7: Patients' views of staff attitude

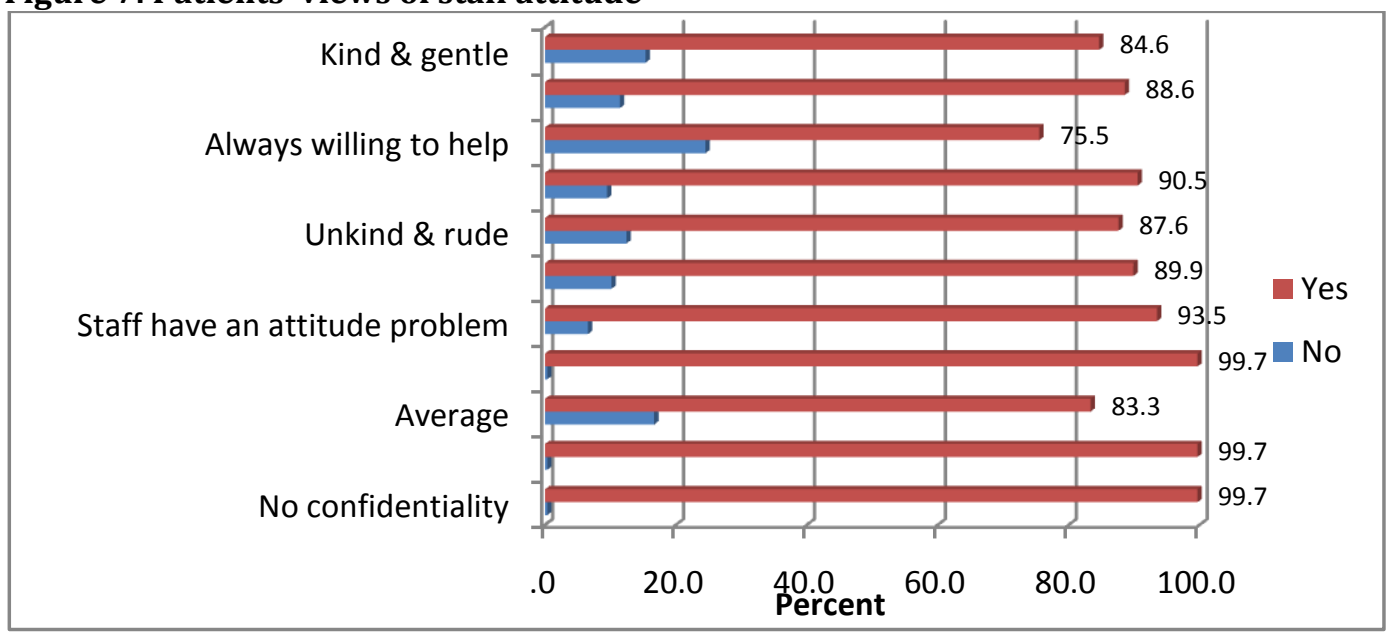

Theme 2: Management practices and Processes

Figure 8: The level of satisfaction of department heads' with their staff

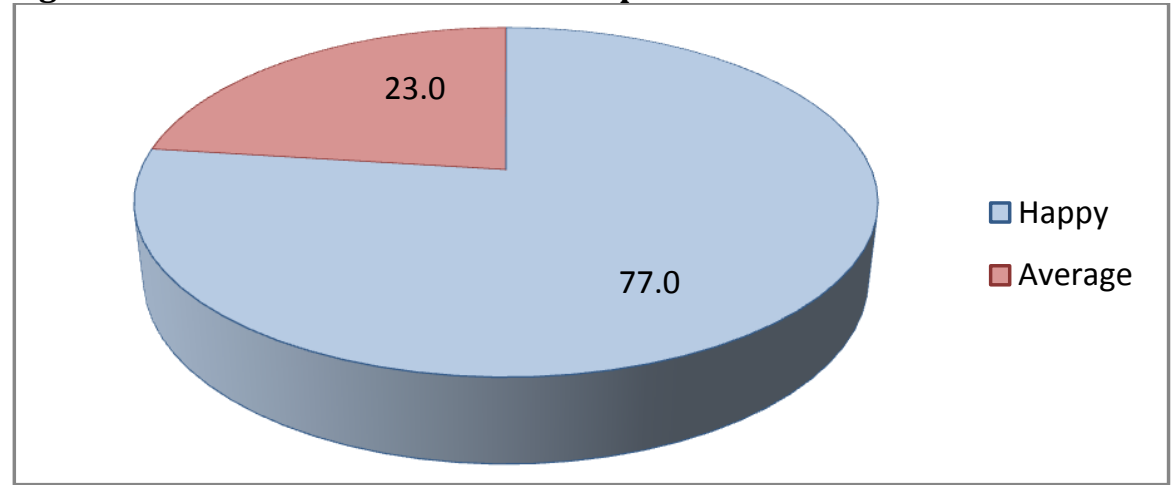

Level of Satisfaction of Department Heads' With Their Staff: Figure 9 indicates the level of satisfaction that managers have with their staff. The satisfaction rating happy: average was in the ratio of 3:1. These findings reveal that majority of management are happy with their staff and is consistent with Olsen, Teare and Gummesson (1996)suggest that to become and remain a leader in a highly competitive marketplace, a hospitality organization needs competent, well trained, highly motivated people who are dedicated to working together and supporting each other. 
Figure 9: Nature of Inter-departmental Complaints

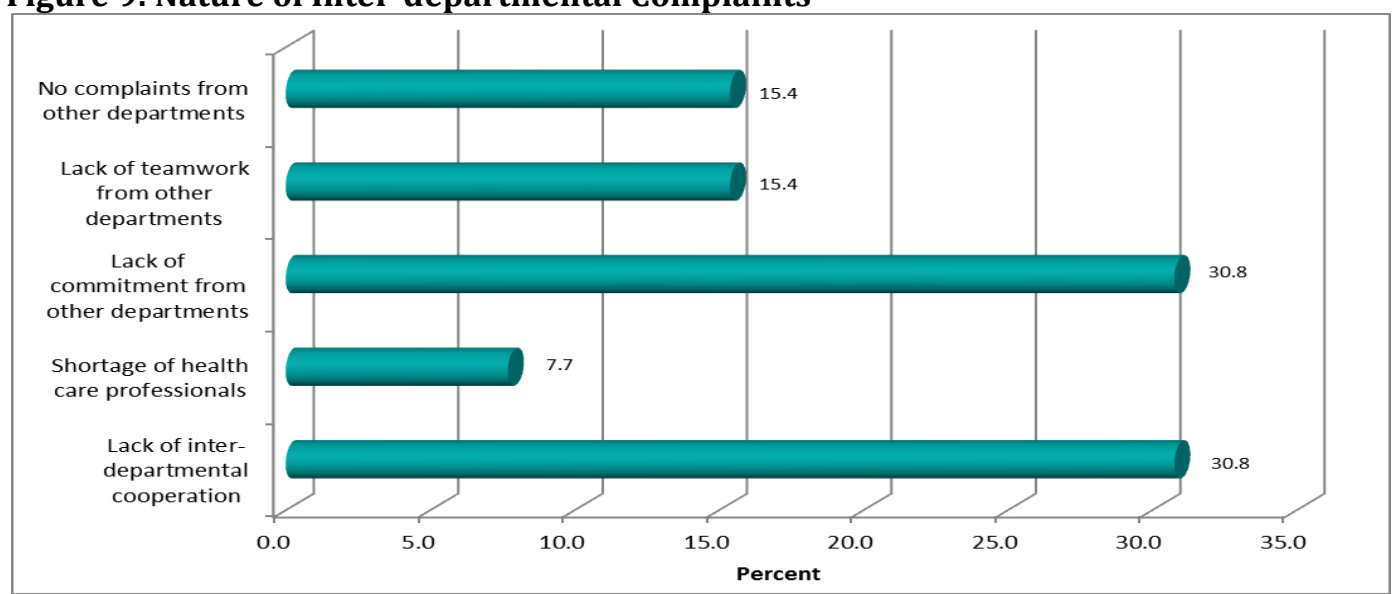

The nature of relations between departments is crucial to a well-synergized organizational operation. Figure 9 two dominant areas, which indicates lack of inter-departmental co-operation and the lack of commitment by between departments.

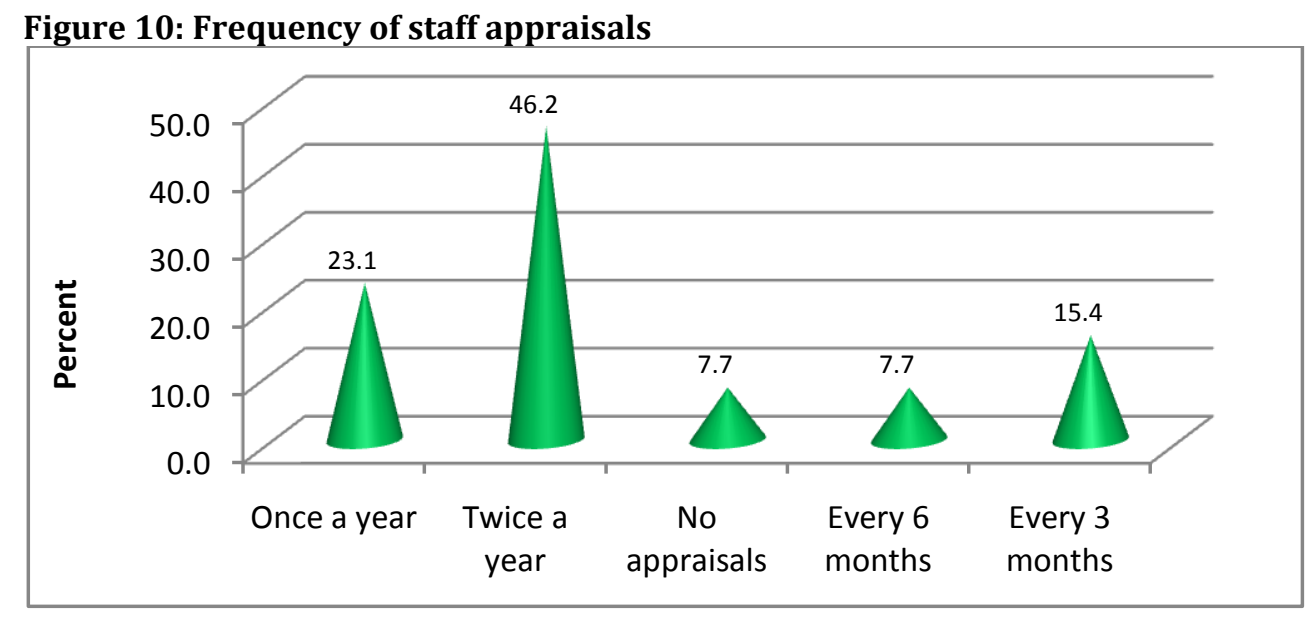

Staff appraisals help track employee performance within the work environment to ensure qualitative service delivery. Figure 10 indicates a varied approach in respect of frequency of this exercise. Appraisals done every three months (15.4\%) leaves little room for development and creares limited space for the employee to function independently.

\section{Figure 11: Nature of staff complaints}

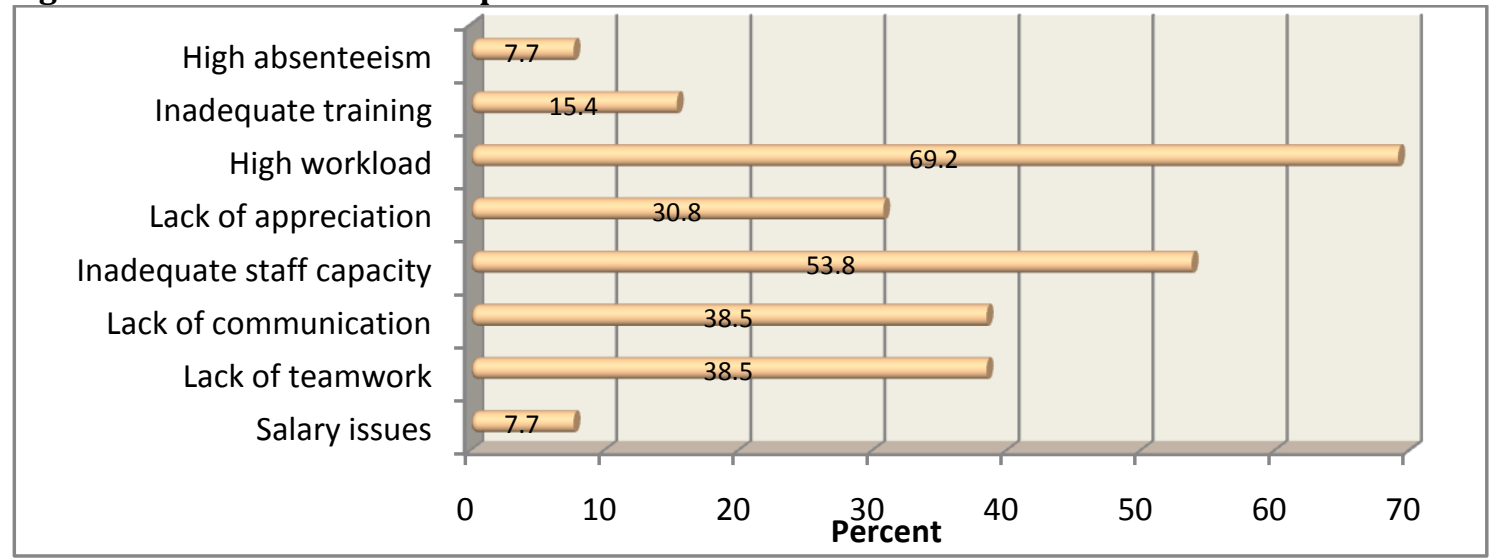

Figure 11 indicates the nature of staff complaints within their department. Multiple responses were possible for this section. The figure represents only the positive results. Figure 11 shows that that the two 
leading complaints from staff were high workload (69.2\%) and inadequate staff capacity (53.8\%). The next leading staff complaints are lack of communication (38.5\%) and lack of teamwork (38.5\%). Staff complaints which follow are lack of appreciation (30.8\%), inadequate training (15.4\%) with salary issues and high absenteeism (7.7\%). This is supported Williams \& Uysal (2003) who concur that in any service industry the service role is basic and essential, and dependant on staff performance, and they further explain (2003: 9) that every employee who is in contact with external customers affects customer satisfaction.

Qualities That the Department Heads Should Have: Top rated two qualities, which stand out as being the most extremely important. These refer to teamwork (84.6\%) and having good communication skills (76.9\%). A second grouping of extremely important rated qualities average around the $60 \%$ response rate. These relate to the character of the individual: punctuality, honesty, empathy and going the extra mile. The ability to organise was not considered as important as there was a less than $4 \%$ difference between usefulness and being extremely important. Findings reveal that the department heads have a modest amount of management knowledge. Mullins (2001) further outlines that the task of management is to make the use of staff, and the responsibility of management is to manage, however the efficiency of staff and their commitment to the aims and philosophy of the establishment are fostered by good human relationships and by the nature of managerial behavior.

Figure 12: Qualities that the department heads should have

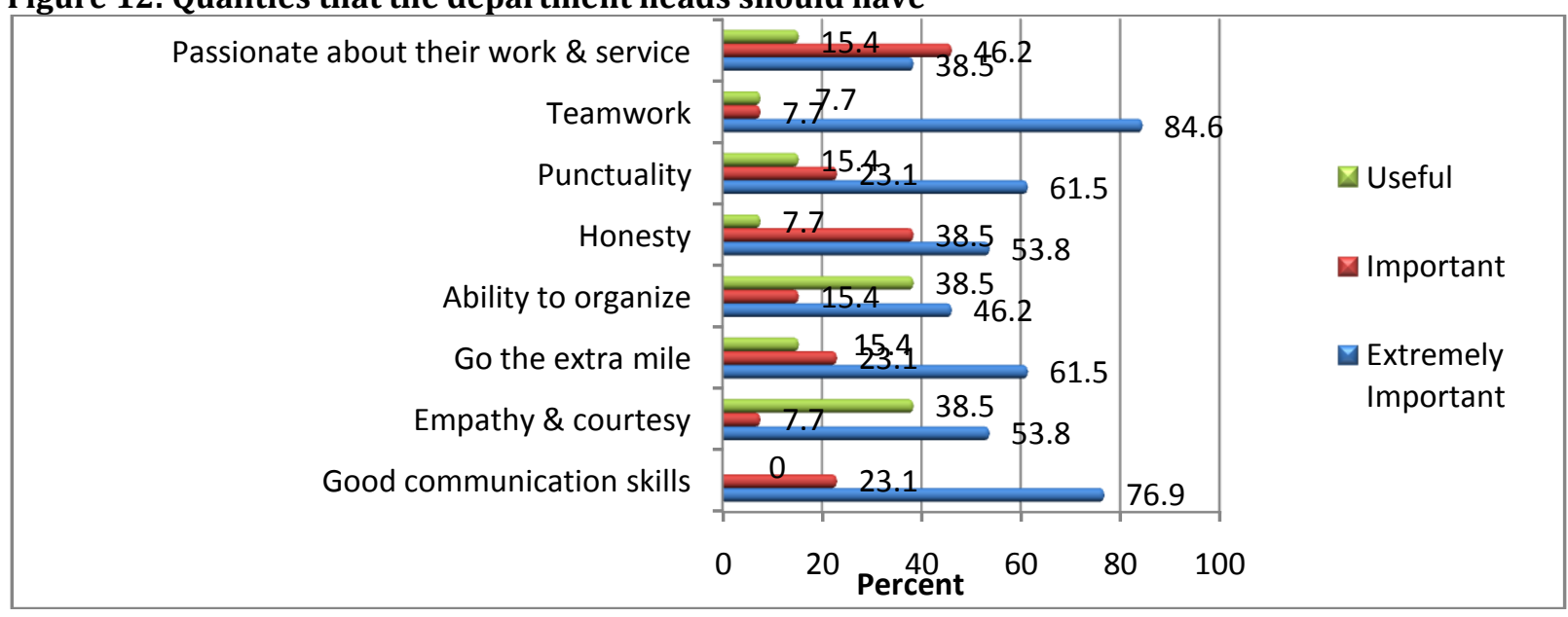

Figure 13: Major challenges that managers encounter during supervision of staff

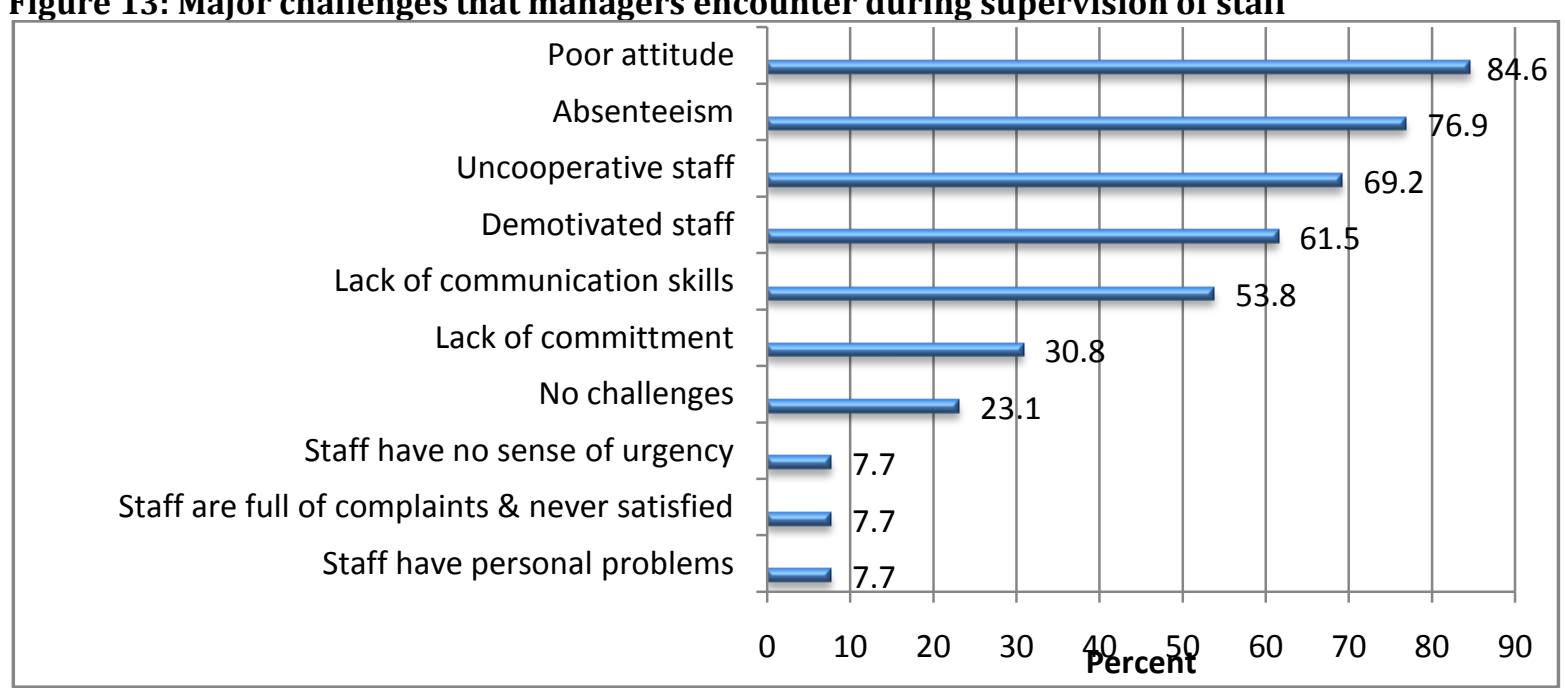

Major Challenges That Managers Encounter during Supervision of Staff: Figure 13 indicates some of the major challenges that managers in the provincial hospital encounter whilst the supervision of staff. Multiple responses were possible for each option. The figure represents only the positive results. Figure 13 shows that the two major challenges of supervision refer to poor attitude (84.6\%) and absenteeism 
(76.9\%). The second grouping of challenges which stand out are uncooperative staff $(69.2 \%)$, staff are demotivated (61.5\%), lack of communication skills (53.8\%) and lack of commitment $(30.8 \%)$. The findings reveal that attitude of staff within the provincial hospital is a major concern. Ford\& Heaton (2000: 142) points out that service effectiveness depends on everyone throughout the organization taking service responsibility seriously and organizations need not hire anyone who is unwilling or unable to provide and deliver outstanding service. The findings further reveal that the major challenge of poor attitude leads to the added challenges that emanate from this attitude.

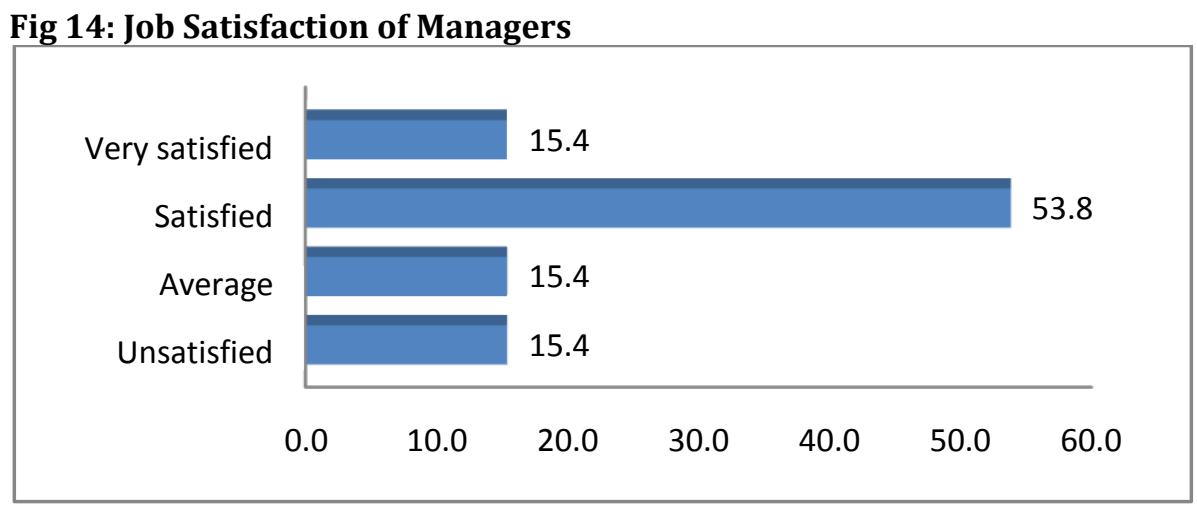

The satisfaction levels of managers contribute largely to the satisfaction levels of staff and in turn the levels of satisfaction of the patients. Figure 14 indicates that almost one third of the managers have opted to choose levels below satisfied.

\section{Figure 15: Workload satisfaction}

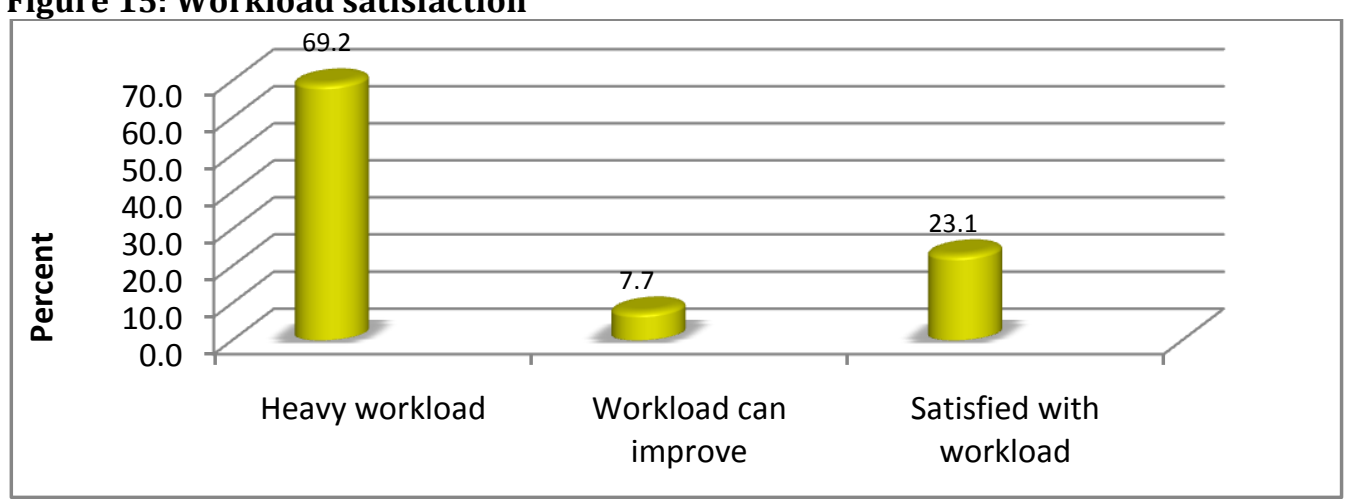

South African public hospitals are typified by short- staffed operations with the hospital. This in turn affects the workload of the limited staff members. Figure 15 shows almost $70 \%$ of staff have workloads that are depicted as heavy. This results on errors within the hospital operations as well as limited capacities to deal with patients effectively.

\section{Conclusion and Recommendations}

The study provides the following conclusions:

- Service delivery can be improved and a fair measure of patients experience poor device delivery in one way or the other;

- The Batho Pele principles have not been adhered to and this is in conflict with the Governments national imperative of serving the people;

- A key contributor to poor service delivery is the problems found in the management processes and practices

In light of the conclusions above, the following recommendations are made which are linked to both service delivery and management processes and practices:

- A work and systems study of the Outpatients and Pharmacy departments with a view to streamlining their operations and clearing their bottlenecks; 
- Visitor facilities such as parking and clear information and communication systems need to be implemented;

- Waiting times to be drastically reduced by increasing staff capacity and developing systems with appointments;

- Create cohesiveness within and between departments through teambuilding exercises and through improvement of communication between staff;

- Staff appraisal should take place once a year and this should be consistent with all staff;

- Workload of staff must be reassessed with a view to introducing new technologies to increase efficiencies;

- Staff development programs must help to build capacity as well as improve staff relations with patients and visitors;

- Absenteeism must be curbed by a strict means of control as well as incentivizing regular and punctual attendance; and

- Senior management must provide greater support to middle managers in respect of counseling, advice, development and future planning.

\section{References}

Berger, F. \& Brownwell, J. (2009). Organizational Behavior for the Hospitality Industry. Upper Saddle River, N.J.: Pearson Prentice Hall.

Blaxter, L., Hughes, C. \& Tight, M. (2006). How to Research. Maidenhead: Open University Press.

Chetty, K. (2009). RK Khan Hospital [online]. Available at: http://www.kznhealth.gov.za/rkkhanhospital.htm [Accessed at 28 November 2009].

Du Toit, D., Knipe, A., Van Niekerk, D., Van der Walt, G. \& Doyle, M. (2002). Service Excellence in Governance. Sandown: Heinemann Publishers.

Ford, C. \& Heaton, C. P. (2000). Managing the Guest Experience in Hospitality. Albany, N.Y.: Delmar/Thomson Learning.

Fraser-Moleketi, G. J. (2007). Batho Pele: Together beating the drum for Service Delivery [online]. Available at: http://www.dpsa.gov.za/batho-pele/index.asp[Accessed 10 August 2009]

Goldenberg, S. (1992). Thinking Methodologically. New York: Harper Collins Publishers Inc.

Hansen, M. H., Hurwitz. W. N. \& Madow, W. G. 1993. Sample Survey Methods and Theory. New York: John Wiley \& Sons.

KwaZulu-Natal Department of Health. (2001). Visions, Missions and Core Values [online]. Available at: http://www.kznhealth.gov.za/vision.htm Accessed 1 November 2010].

KwaZula-Natal Health Act, No. 4 of 2000 [online]. (2000). Available at: http://www.kznhealth.gov.za/healthact.pdf [Accessed 15 April 2009].

Kotas, R., Teare, T., Logie, J., Jayawardena, C. \& Bowen, J. (1996). The International Hospitality Business. London: Cassell.

Moore, N. (1983). How to do Research. London: The Library Association.

Mullins, L. J. (2001). Hospitality Management and Organizational Behavior. Harlow, Essex: Longman.

Neuman, W. L. (2006). Social Research Methods: Qualitative and Quantitative Approaches. Boston: Pearson Education.

Nzimakwe, T. I. \& Mpehle, Z. (2012). Key factors in the successful implementation of Batho Pele Principles [online]. Journal of Public Administration, 47(1.1) 279 - 290.

Olsen, M. D., Teare, R. \& Gummesson, E. (1996). Service Quality in Hospitality Organizations. London: Cassell.

South African Government Information: Health [online]. (2008). Available at: http://www.info.gov.za/aboutsa/health.htm[Accessed 10 May 2009].

Williams, J. A. \& Uysal, M. (2003). Current Issues and Development in Hospitality and Tourism Satisfaction. Binghamton, N.Y.: Haworth Hospitality Press.

Whitney, L. D. (1990). Ethics in the Hospitality Industry: With a focus on Hotel Managers. International Journal of Hospitality Management, 9(1), 59-68.

\section{Unstructured Interviews}

Chetty, K. (2010). Interviewed by A. Deen. RK Khan Hospital, Durban, 30 March 